\title{
Research on the Refined Management of Research Projects of Finance and Economics University.
}

\author{
JiaLiu, ${ }^{1, a}$, Wei Wen ${ }^{2, b,{ }^{*}}$,Yanjie Li ${ }^{3, c}$ \\ ${ }^{1}$ No.121, zhangjialukou, fengtai district, Beijing. \\ ${ }^{2}$ No.121, zhangjialukou, fengtai district, Beijing. \\ ${ }^{3}$ No.121, zhangjialukou, fengtai district, Beijing. \\ awdbaby0122@126.com, bwenwei@cueb.edu.cn, cliyanjie@cueb.edu.cn
}

Keywords: University of finance and economics; Scientific research project ; Refined
management

\begin{abstract}
Basic research in our country is in the new stage of the innovation and development, it is also the depth adjustment of the innovation system of science and technology system . For strengthening the construction of a think-tank and science communication, the development of scientific research in higher educational institutions should be devoted to improve the ability of scientific decision-making service, promote scientific influence to society. Refined management of scientific research project can help improve the using efficiency of funds, and the level and quality of scientific research in colleges and universities.
\end{abstract}

\section{Introduction}

Refined management originated from the "principles of scientific management" by Taylor, the father of scientific management in the United States in 1911, which is the product of social division of labor. Refined management is the second level of scientific management. Its core idea is to minimize the resources occupied by management to reduce management costs and improve production efficiency [1]. Subsequently, American professors Zhu Lan and Deming put forward the viewpoint of quality management control, which unified the refined management and quality. Although the advanced refined management idea is proposed by American scholars, it has been greatly developed in Japan, such as "Toyota production mode" and "6 $\sigma$ management." The research on refined management in China began with the "refined management project"which proposed by Liu Xianming in 2001. Wang Zhong proposed the concept of fine management firstly in the book "detail decides success or failure", 2004. Over the next decade, refined management theory booming developmented among colleges and universities, hotels, enterprises and institutions such as government management to practical account. ${ }^{[2 \sim 3]}$ With the in-depth development of the reform of the management system of colleges and universities, the application of the refined management concept to guide the development of enterprises is obviously of pioneering significance to the management of scientific research projects in university of finance and economics.

\section{Management of scientific research projects in university of finance and economics.}

Scientific research management in colleges and universities of finance and economics is the management activities in the process of planning and designing, organization and management, internal control and summary ,including the items people, goods, content, time, information. Then achieve the scientific target management activities. University scientific research management activity has the following several characteristics: one is systemic, from input to output programs to promote activities which is a complete system, needing comprehensive consideration of human, financial and coordination and configuration. The second is human nature, the subject and object of scientific research management are the participants of scientific research work, which should be taken into account the personality and characteristics of people in the process of scientific research 
service. Third, the complexity of scientific research management activities involves a wide range of personnel, a large amount of funds, a large number of services, and the intersection of academic disciplines. The management of scientific research has become more complex. ${ }^{[4 \sim 7]}$

Therefore, with the unceasing change of scientific research environment and social environment, finance and economics college scientific research management work is also in constant innovation and development, also calling for the scientific research management personnel constantly improving the business level, perfecting management system and management methods, improving the efficiency of scientific research management.

\section{The refined management - taking the national natural science foundation project as an example which datas from "S"university.}

The "S" university of finance and economics in Beijing has been funded by the national natural science foundation (here in after referred to as the "science fund") for 27 years since 1991. Rapid development of science fund provides more and more broad development space for $S$ university researchers. Increasing grants, expanding fund project scale, management system innovation promted S university science and technology subject development. "Twelfth five-year" period, the research department of " $S$ " university continuously explored the innovation of science fund management modes and methods. And gradually applied the excellent management, refined management thoughts to the management of national scientific research project. They have made beneficial attempts in innovation system and perfect supporting policies, and achieved certain results.

\subsection{The overall analysis of the application and funding of science funds for 1996-2017.}

\subsubsection{Development of science fund.}

The development process of science fund research of $\mathrm{S}$ university is mainly divided into three stages. The first stage is from 1991 to 2005, which is the period of scientific research and exploration. This period is still in the period of shortage of scientific research talents and weak research foundation. And the importance of school for teaching was higher than that of scientific research. At this stage, people who tried to apply the science fund project were less, approving number was between 1 and 2.After the grant amount has been substantially increased, the number of applications has gradually increased. Researchers have a long time to grasp and respond to the development of scientific research.

The second stage, from 2006 to 2011, is the accumulation period of scientific research ability. As the national "11 th five-year plan" period of science and technology innovation, the public put forward new requirements and a series of measures to promote the development of scientific research. Universities and researchers paid more attention to improve their scientific research ability and level, to shift thier focusment on the country's social development and national economy and people's livelihood problems, combining scientific research and social practice, gradually achieved many scientific research achievements. In this stage, the number of applications for science funds has been greatly improved, and the number of approved grants has increased correspondingly, and the grant funding has also exceeded the previous period, which has laid a good foundation for the scientific research in the new era.

The third stage is the development period of scientific research since 2012. Approved national project number has become one of the important indicators to measure the level of scientific research in higher educational institutions. Universities encourage the school scientific research personnel for scientific research and innovation work through the management system, funds support, reward, examine, etc. These measures has obtained remarkable effect in this phase. Whether the national social science fund project or science fund project, the declaration and approval numbers were increased significantly, explosiving growth. In 2016, 30 national social science fund projects were approved, ranking no. 1 in the university of Beijing municipal universities. Approved science fund project 20, ranking 10th in the national finance and economics universities. 


\subsubsection{Development characteristics of science fund.}

1.The number of applications and approvals has increased year by year and remained stable.

Can be seen from Fig.1, the number of science fund of the applications in the overall trend is rising, and after 2013 it has maintained a higher level. In 2016 the number reached a peak of 83 at present, it provides the approved amount and scale to increase the premise and guarantee.

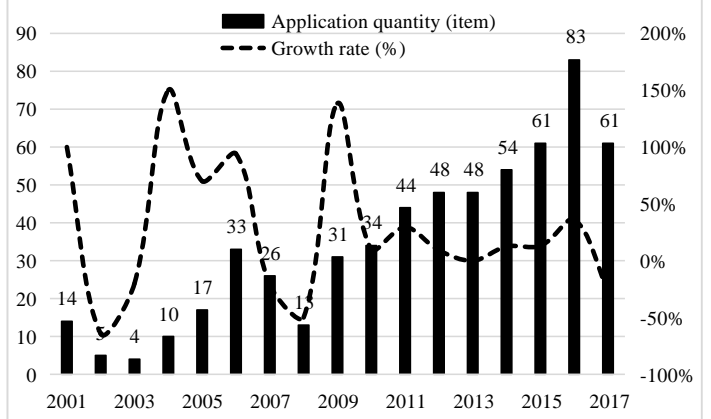

Fig.1. The apply project of the national natural science foundation in 2011-2017.

As can be seen from the Fig.2, although science funds approved by the project number fluctuated, but in the longitudinal direction it is still upward development trend. After 2014, the number of approved batches exceeded 10 each year and reached the current peak of 20 in 2016.

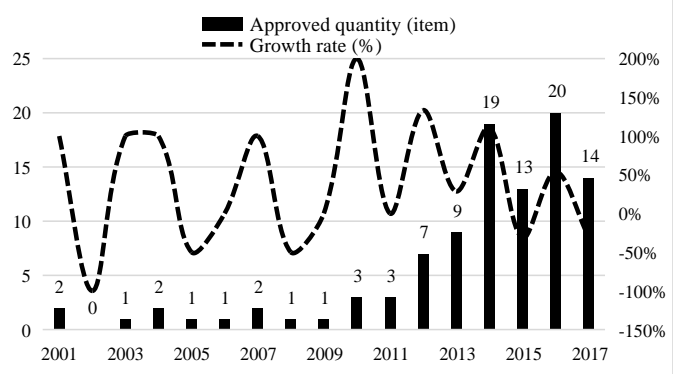

Fig.2. The project approval of national natural science foundation in 2011-2017.

2.The high-level scientific research team is gradually formed.

Among the applicants of Science fund project, Dr and above degree reached $71.43 \%$, the proportion of the proportion of young lecturer was at $49.52 \%$ (see Fig. 3). The promising young educated researchers become a mainstay of $\mathrm{S}$ university scientific research personnel system, promoting scientific enterprise vigorous development. More than $50 \%$ of the applicants having senior and senior titles, these applicants have the characteristics of strong research foundation and strong research continuity, etc.. Their research output can be the landmark with significant influence of scientific research. They are the backbone of the application for science funding and major projects.

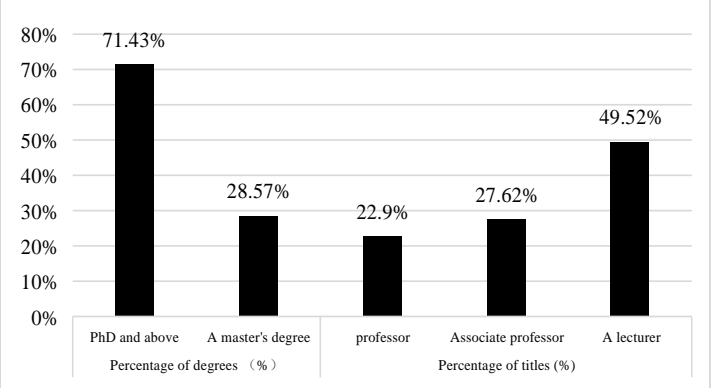

Fig. 3.1991-2017 national natural science foundation project leader degree and professional title statistics.

3.The amount of funding gradually increased and the initial scale was formed.

With the increasing approved number of scientific funds, the amount of research fund is also increasing, the annual average fund being over 3 million yuan (as shown in Fig.4). For financial and economic colleges and universities, the funding is large enough, and forming a certain scale. Approved projects also produced a lot of support with large amounts of individual projects. That 
means $\mathrm{S}$ university in some disciplines has the research abilities to solve important and key problems, providing enough support.

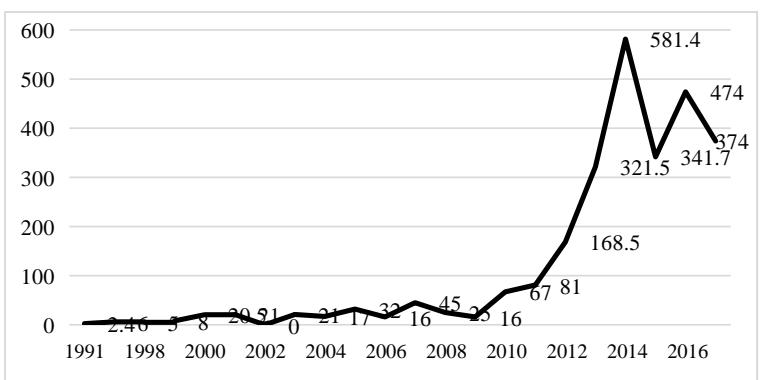

Fig.4. The national natural science foundation grant amount (ten thousand yuan).

4.The distribution of subjects gradually expanded and diversity increased.

From 1991 to 2017, the distribution of science funds was gradually expanded (as shown in Fig.5). In the initial application period, it was mainly concentrated in the management field, with a proportion of over $60 \%$. Under the condition of equilibrium development layout by S university, the late approved projects' rangement has been expanded step by step, from mathematics, physics, geography and metallurgy to construction environment and structure engineering, automation disciplines such as multiple disciplines. In the case of a substantial increase in the number of approved projects, dominant disciplines are continuing to lead, and Other disciplines also have zero breakthroughs. It is a beneficial attempt to increase the diversity of science fund project approved variety development in the discipline, also is advantageous to the school comprehensive research strength, expanding academic influence.

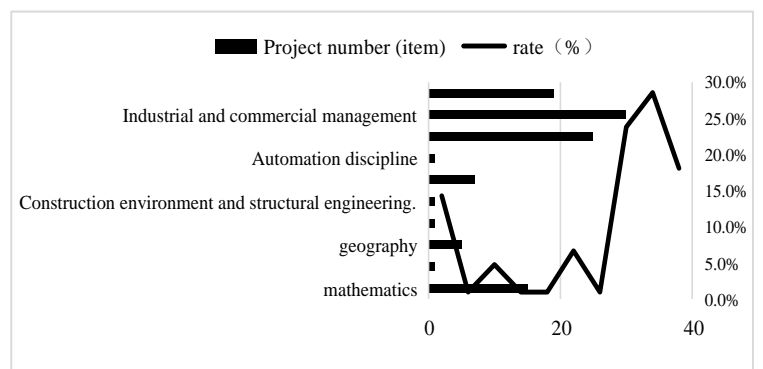

Fig.5.1991 -2017 The national natural science fund project discipline distribution.

\section{The detailed refinded management measures and results of the scientific research projects .}

\subsection{Carry out the training plan for scientific research, and cultivate the elite scientific research} team.

To establish a scientific talent support system. The scientific research management department of S university has carried out a series of plans to cultivate talents for scientific research. Firstly, they focus on cultivating academic talents and strengthening its academic leading role. At the same time, the young talents are encouraged and supported by financial policies and other aspects, so as to cultivate young cadres with higher ideological awareness and high quality of scientific research. As shown in Fig.6, in the applications of science fund, the proportion of 35-year-old young academic cadre is the largest. 


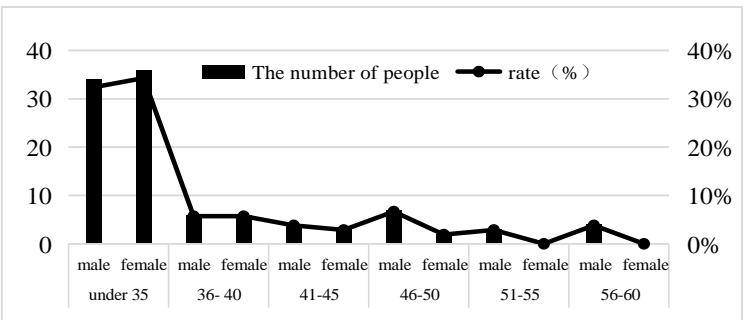

Fig.6.Age and gender distribution of the national natural science foundation project.

\subsubsection{To start the fund plan for new teachers}

Since 2013, in line with the school talent introduction and training, further implementing the strategy of talent strong school to create a good research conditions and the environment, improving young teachers' scientific research ability, and to give full play to the role of young teachers in teaching, scientific research and discipline construction in our school, the $\mathrm{S}$ university launched a "New teachers start fund project". To provide a certain amount of fund for the new young teachers to carry out the basic research of scientific research projects, and to lay the foundation for the application of high level scientific research projects.

\subsubsection{Research project cultivation plan.}

With the deepening of the research and development, S university put forward the idea "research that using" to improve the efficiency of the using of scientific research funds. So a series of important scientific research achievements, output and the symbolic achievements can be achieved. And aslo improving the level of scientific research in schools and encouraging young talents to stand out. In order to lead the scientific research team to cooperate, realize the research frontier with the national key projects, $\mathrm{S}$ university has carried out the "research project incubation program". And strive to make pre-research and coordination work for the national level, the ministry of education and the major scientific research projects in Beijing.

4.1.3 Select the leader of the reserve discipline and young and middle-aged backbone teachers. In order to further improve the middle-aged and young teachers training system, strengthen discipline echelon construction, S university's scientific bureau and personnel took the "reserve the leader, the backbone of middle-aged and young teachers training plan", then to establish academic echelon with training to adapt to the school development goals. From 2010 to now, there have been 71 training leaders and 112 middle-aged and young teachers. In the process of national scientific research projects, these talents have played a vital role in the development of China's scientific research projects. As shown in table 1, the national natural science foundation of $\mathrm{S}$ university was approved for 88 projects from 2010 to 2017. Among them, the reserve discipline leader and the young and middle-aged backbone teachers received 32 items, accounting for $35.23 \%$ out of the total. In particular, between 2011 and 2013, the proportion was more than 66 percent.

Taking the science foundation as an example, among the 91 fund projects that approved, the youth projects werer 58 , accounting for $63.74 \%$. The school personnel training plan has played a more significant positive role when applying for science fund project. It encouraged researchers to study morale and enthusiasm and laid a strong talent base for $\mathrm{S}$ university scientific research and development.

Table 1.2011-2017 national natural science foundation project reserve discipline leader and junior and young backbone teacher status.

\begin{tabular}{cccccccc}
\hline & $\begin{array}{c}\text { Project } \\
\text { quantity (item) }\end{array}$ & $\begin{array}{c}\text { Middle age and } \\
\text { youth (item) }\end{array}$ & rate $(\%)$ & Back-up (item) & rate (\%) & Toutal (item) & rate $(\%)$ \\
\hline 2010 & 3 & 1 & 33.3 & 0 & 0 & 1 & 33.3 \\
2011 & 3 & 2 & 66.7 & 0 & 0 & 2 & 66.67 \\
2012 & 7 & 3 & 42.86 & 2 & 33.3 & 5 & 71.43 \\
2013 & 9 & 4 & 44.44 & 2 & 25 & 6 & 66.67 \\
2014 & 19 & 7 & 36.84 & 0 & 0 & 7 & 36.84 \\
2015 & 13 & 1 & 7.7 & 0 & 0 & 1 & 7.7 \\
2016 & 20 & 6 & 30 & 3 & 15 & 9 & 45 \\
2017 & 14 & 3 & 21.43 & 2 & 14.29 & 5 & 57.14 \\
Toutal & 88 & 23 & 26.14 & 9 & 10.23 & 32 & 35.23 \\
\hline
\end{tabular}




\subsection{Improve the organization and management functions of the entrusted organization for improving the quality of application and accomplishment.}

The scientific fund managers have to uphold the idea of excellent management, orderly and effectively to do a good job of annual application. Then establish a set of effective and scientific management process and system to provide guarantee for successful application science fund project.

4.2.1 Well-organized application system.

(1) To set clear goals for application preparation.

When applying for scientific research fund project, the $S$ university will apply for the preparatory stage before. The starting point is the key to the whole time node for preparing, strategic deployment activities have become a centerpiece of scientific research management department. The effective training layout model adopted by S university are: from top to bottom, from the whole to the local, from classification to discipline.

(2)Application for review-details determine success or failure.

The scientific research project management department plays an important role in the application of the research fund project. Management personnel should master fund management in comprehensive regulation and the method of project guidelines, funds management, etc.. Under the above conditions, Management personnel should checkeach project carefully including the deals of director and participates' application conditions, and seeing if there is any filling, wrong fill, fill in wrong position, ensuring that there is no errors in the format, reduce the review.

As the number of applications for science funds has increased in recent years, and the composition is more complicated than before, higher requirements and challenges are put forward in refined management. Project managers must establish effective linkage mechanism to ensure that details are managed within a limited period of time. Therefore, every application needs to br reviewed at least tiwice. only after confirmed that no obvious errors and omissions to the project management department. The applications will be reported to the superior project management department only by confirming that there are no obvious errors and omissions.

Under the guarantee of the above application work, the establishment rate of scientific fund is also continuously improving, and the approval rate for the three consecutive years from 2014 to 2016 is more than 20\%, as shown in Fig.7.

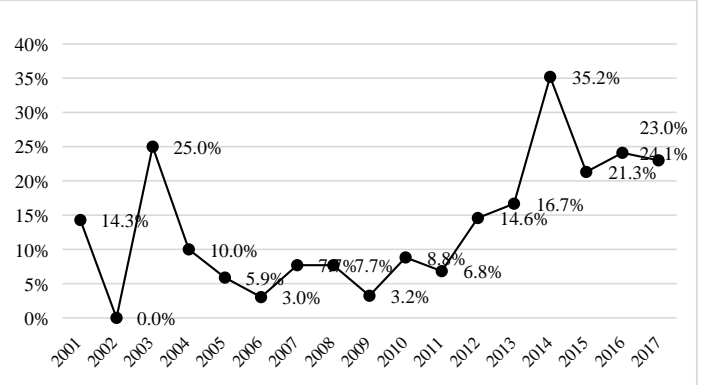

Fig.7.2001-2017 the approval rate (\%) of national natural science foundation.

4.2.2 Establish an annual inspection and warning system -- advancing the project progress.

After the approval of the science fund project, the scientific research management department shall reconfirm the budget, expected results and time of the project, and establish the relevant project library for follow-up management. The specific practice mainly includes: firstly, after the scientific research fund reaches the school finance department, the project fund account should be sent to the scientific research staff in time to provide timely financial guarantee for the project. It also keeps track of the usage of funds in each quarter, and requests the project leader to give timely feedback to the scientific research performance. Secondly, timely inform the project leader to fill in the annual inspection report on the website of national natural science foundation to prevent missing the filling time. Thirdly, for the projects that annual performance and funds using unreasonable , the scientific research managers will urge project leaders to intensify research progress.If there is a need to apply for an extension, the scientific management department needs to conduct a strict review in advance. If 
true, it will be applied to the higher level units. Otherwise, if the delay reason is insufficient to support the extension request, the supporting unit will reject the extension application.

Under the above system, the annual inspection and results of scientific funds are ideal.

4.2.3 Establish a prejudging system to improve the quality of the results.

To improve the research level of scientific research projects. The scientific research department of the school shall strictly control the academic quality of the project results. They formulate the pre-evaluation system of scientific research projects at the provincial and ministerial level in order to improve the quality and level of scientific research projects, so as the pass rate.

The pre-evaluation system requires the project leader to organize 5 senior experts from different legal entities to conduct the project outcome conference assessment seminar.The experts put forward corresponding questions on the project results, and formed a review opinion to help the project leader modify the project results and improve the scientific and rigorous results. After discussion and revision of the project results, the project management department can submit the project appraisal to the superior project management department.

As shown in Fig. 8, it can be seen that the final acceptance work of projects before 2012 was all completed. The project of 2015-2017 is not yet up to date. From 2012 to 2014, the rate of project settlement has decreased. This is more closely related to the increase in the number of projects and the extension of research applications and the requirements of schools.

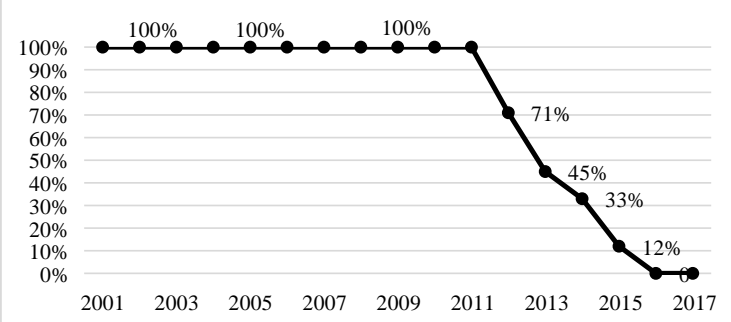

Fig. 8.2001-2017 the junction rate (\%) of national natural science fund.

\subsection{Establish a matching system for fund awards to mobilize the enthusiasm of scientific research personnel.}

To fully mobilize the enthusiasm of scientific research personnel for scientific research and innovation, $\mathrm{S}$ university has developed a matching fund and reward management method for scientific research projects. The supporting scope of the above methods includes all vertical projects of provincial level and above, as well as excellent achievements in scientific research.The range of supporting funds ranges from 60, 000 to 32, 000 yuan. The rewards range from 100 yuan to 50,000 yuan.Since 2004, the school has decided to increase project incentives and introduced a series of encouraging measures to achieve certain results.Take the science foundation as an example, from 2010 to 2016, the proportion of supporting incentive increases obviously, as shown in Fig. 9.Among them, the number of supporting incentives for the establishment and mid-term inspection is increased.The reward of completed projectsis is unstable.This shows how to ensure that deadlines are a major challenge for the growing number of project management jobs.

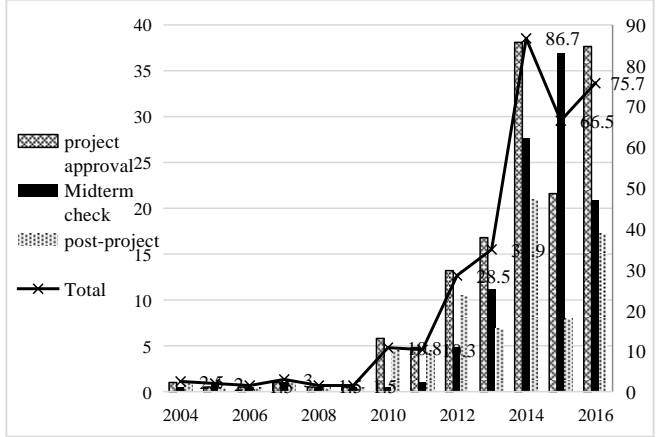

Fig. 9.2004 -2016 the national natural fund approved project matching award(ten thousand yuan). 


\subsection{Good scientific fund project output management can actively promote the transformation .}

From the output of the science fund project from 1991 to 2016, the number of papers produced, the number of published monograph and the number of patents have increased. The $\mathrm{S}$ university has the corresponding reward system and method for the core paper and corresponding publications, patents and so on. Results of output and transformation is the important indicators of scientific research level and the scientific research work. It is conducive to the development of science funds and the realization of economic and social benefits by completing the work incentive.

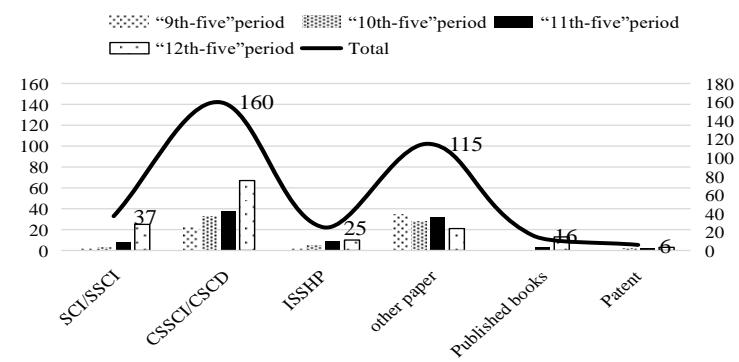

Fig.10.1991-2016 The output of the national natural science foundation project (part, part)

\section{Summary}

The refined management needs to start from the refinement thought, establish the refined system, carrying on the refined implementation. Summarizing specific experiences can be innovated from the following aspects:

\subsection{Carry out refined management innovation, strengthen supporting institution's function.}

To explore reasonable and refined management mechanism is still the management target of supporting institutions. First, we must do a good job in institutional infrastructure.It mainly does the following. First, under the premise of openness and fairness, we should improve the supervision and management mechanism of the scientific fund from planning, filing, establishing the project to the conclusion and producing excellent results.The second is to constantly improve the quality and science of scientific research management objectives.On the basis of the establishment of the early cultivation and the mid-term supporting incentive to promote the later funding and increase support for basic research.Third, reward and encourage the team with good scientific research reputation and outstanding achievements. The researchers who have failed to qualify for the credit and disqualification should be punished.

\subsection{Innovative the refined organizational model of scientific research talents.}

Scientific research innovation plays an important role in China's scientific research field.However, how to combine the scientific research and social development into the scientific and technological productive forces is the problem that the scientific research management department needs to think about.Therefore, it is necessary to innovate and refine the form of scientific research organization.The leaders of scientific research projects should use the project as a bridge to encourage scientific research personnel to create in the form of flexible organization.At the same time, we should gradually break through the barriers of intramural resources, human resources and platform resources to form an open and healthy competition.

\subsection{Establish the talent refinement training mechanism.}

The scientific research management department should cooperate with the personnel department to deepen the reform of personnel appointment system. We may establish a dual-track system for scientific research and teaching, a system of talent selection and selection that emphasizes innovation, 
quality and effectiveness.Let the talent flow, constantly optimize the scientific research team structure.

\subsection{Establish a refined mechanism for the transformation of scientific achievements.}

The ultimate goal of research project research is to strengthen basic research and translate applied research into beneficial results of society.The strength of individual and team members is limited, so it is necessary for the scientific research management department to provide funds, information platform, external communication and other support for the transformation of outstanding achievements of the fund.

Through the efforts of the scientific research management department, the excellent scientific research achievements of universities are collected, displayed, packaged and promoted in batches and in batches. Through the communication and collaboration between schools and governments and enterprises, the results are applied to practice.The results can improve the economic, social and cultural benefits of the project by transforming it into social cultural products, government decision-making and teaching materials.

\section{References}

[1] Li Xinchun, Hu Xiaohong. Principles of scientific management: theoretical reflection and realistic criticism, Journal of management,vol.05,pp.658-670, 2012.

[2] Luo Kaiping, Zhang Renqian, Wang Huiwen. A new method for predicting the application of national natural science foundation project, Scientific research management,vol.04,pp.152-160, 2016.

[3] Zheng Shiming, Ren Liuqing. Performance evaluation and influencing factors of young science fund project,China science foundation,vol.03,pp.255-261, 2016.

[4] Xu Min. Research on the growth model of young talents in basic research,Science and technology management,vol.02,pp.132-138, 2015.

[5] Liu Shuangqing, Wu Xiaosong, Chen Guang, Wang Quwu. Analysis of project funding of the life science department of the national natural science foundation of hunan province from 2009 to 2014,China science fund,vol.02,pp.148-152, 2015.

[6] Yu Qian, Ma Junjie, Liu Yaqin. Analysis on the effectiveness of the research group fund of innovation based on innovation group cultivation, China science foundation,vol.02,pp.99-107, 2015.

[7] Zhang Jiangli, Lin Kejian. Management effect and thinking of the national natural science foundation of China academy of agricultural sciences, China science foundation,vol.03,pp.232-235, 2014. 